\title{
Variability of CODG TEC and IRI 2001 total electron content (TEC) during IHY campaign period (21 March to 16 April 2008) at Niamey under different geomagnetic activity conditions
}

\author{
Frédéric Ouattara ${ }^{1 *}$ and Rolland Fleury ${ }^{2}$ \\ ${ }^{1}$ Ecole Normale Supérieure de l'Université de Koudougou, BP 376 Koudougou Burkina Faso. \\ ${ }^{2}$ ENST Bretagne Technopole Brest Iroise, 29239 Brest, France.
}

Accepted 27 July, 2011

\begin{abstract}
IRI 2001 model prediction is compared to custom orthotic design group total electron content (CODG TEC) maps prediction at Niamey during several geomagnetic (quiet, fluctuating and shock days) conditions for the period of IHY campaign. Independently of geomagnetic conditions, the qualitative comparison between CODG TEC maps and IRI 2001 TEC shows the overestimation of IRI 2001 model. The overestimation of CODG TEC maps at Niamey by IRI model is also shown by examining quantitative methods (relative deviation module means $(\mathrm{rdmm})$ and percentage deviation) results. The quality of IRI prediction, that is, the amplitude of estimation depends on geomagnetic condition and month. In fact, rdmm values of March and April for quiet day periods respectively are 0.53 and 0.41 . During fluctuating period, rdmm values are 0.35 in March and 0.39 in April. When act CMEs, rdmm value is 0.67; thus the work shows on one hand the necessity to improve IRI model and on the other hand to study the effect of each disturb solar event separately.
\end{abstract}

Key words: Total electron content, custom orthotic design group, international reference ionosphere, geomagnetic classes of activity, relative deviation module means, percentage deviation, concordance.

\section{INTRODUCTION}

The climatology of critical frequency of F2 layer (foF2) and total electron content (TEC) at Ouagadougou station (Geo latitude: $12^{\circ} 21^{\prime} 11.52$ ' N; Geo longitude: $-1^{\circ} 30^{\prime}$ 44.71" E) showed that ionosphere reacts differently under different solar events and according to sunspot cycle phases and seasons (Ouattara, 2009; Ouattara et al., 2009). By considering the role of ionosphere in telecommunication, it seems important to determine by prevision the state of ionosphere during solar events. For that, models have been developed, validated and/or improved by using in situ measurement data [for example, international reference ionosphere (IRI); semiempirical low latitude ionosphere model (SLIM) (Anderson et al., 1985) and parameterised ionospheric

\footnotetext{
${ }^{*}$ Corresponding author. E-mail: fojals@yahoo.fr.
}

model (PIM) (Daniell et al., 1995)]. Other validated dynamo theory [for example, global theoretical ionospheric model (GTIM) (Anderson et al., 1996) and coupled thermosphere ionosphere plasmasphere model (CTIPM) (Schunk, 1996)]. The lack of measured data in Africa shows the problem of validating existing models as planetary models. During international heliophysical year (IHY) program, many instruments were installed in Africa such as magnetometers and global positioning system (GPS) stations. Figure 1 shows GPS stations in Africa. We distinguish: 1) international geodesy system (IGS) stations in sky blue square, 2) University Navstar Consortium (UNAVCO) stations in black square; 3 ) National Oceanic and Atmospheric Administration (NOAA)/continuously operating reference station (CORS) stations in red square, 4) other stations in pink square including Koudougou station (Geo latitude: 12.24 N; Geo longitude: $357.61^{\circ} \mathrm{E}$ ), 5) AMMA (Analyse Multidisciplinaire 


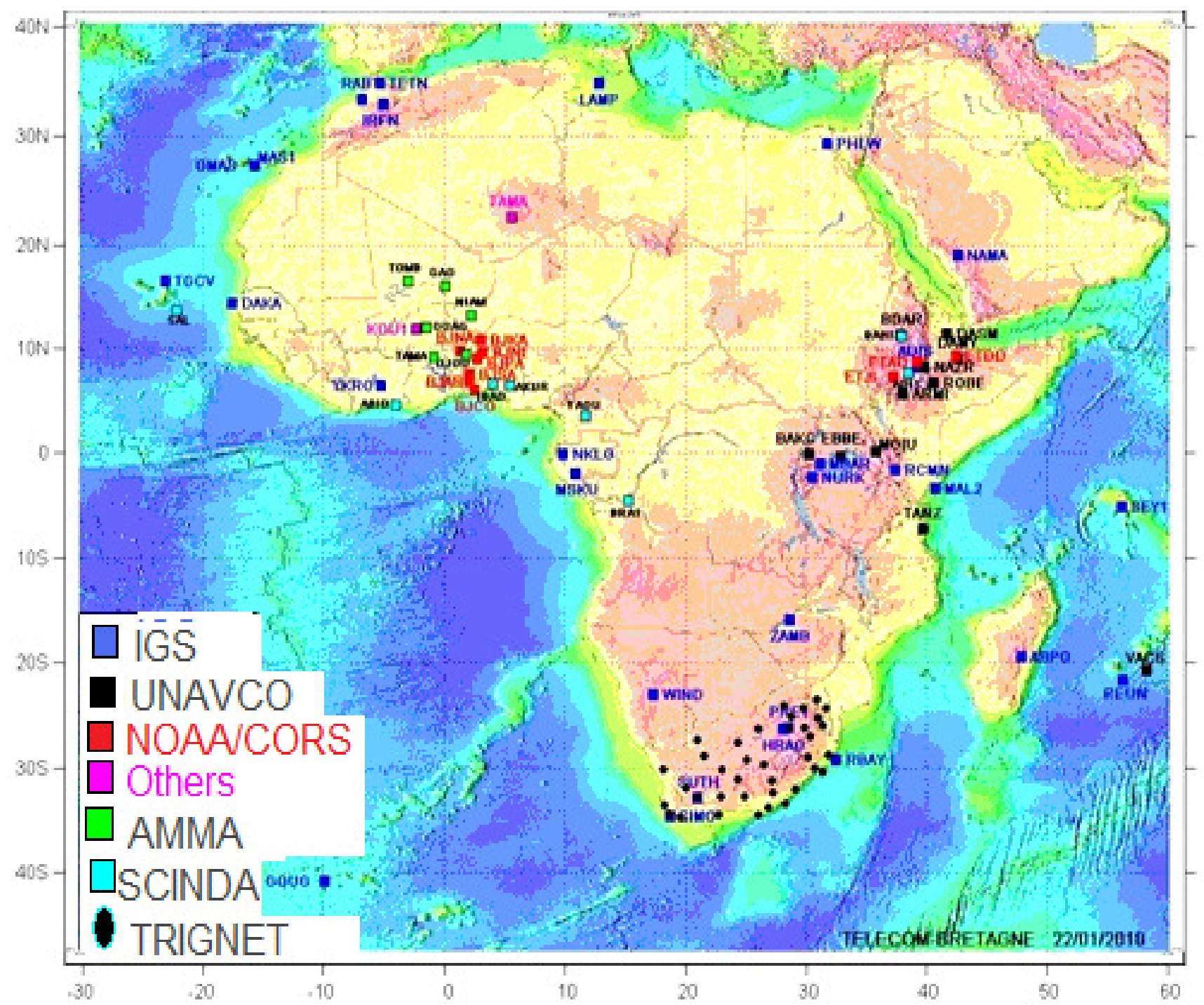

Figure 1. Map of Africa GPS network (Fleury, 2010).

de la Mousson Africaine) stations in green square including Niamey station, 6) SCINDA (scintillation network decision aid) in blue square, and 7) TRIGNET in black circle. This is South Africa GPS network. For IHY first campaign, we have 9 African GPS involved: 8 SCINDA GPS and 1 GPS of Groupe International de Recherche Europe Afrique (GIRGEA) which is Koudougou GPS (Amory-Mazaudier et al., 2008). Figure 2 shows the stations used in CODG TEC maps.

The comparison between Figures 1 and 2 allows us to state that only 4 SCINDA GPS stations are involved in the determination of custom orthotic design group total electron content (CODG TEC) maps: 1 station in Côte d'Ivoire, 1 station in Cape Verde and 2 stations in Nigeria. Koudougou GPS data are not yet included in CODG data base. IHY campaign aims at collecting data in order to reduce the gap between Africa and the rest of the world (Figures 1 and 2) and to improve the existing ionospheric models. With old (ionosonde) and new (GPS) data, we have an opportunity to improve ionosphere model in equatorial region. Obrou (2008) uses ionosonde data of Korhogo (Geo latitude: 9,3N; Geo longitude: 354, $62 \mathrm{E}$ ), Ouagadougou (Geo latitude: $12^{\circ} 21^{\prime} 11.52^{\prime \prime} \mathrm{N}$; Geo longitude: $-1^{\circ} 30^{\prime} 44.71$ ' E ) and Dakar (Geo latitude: 14,685 N ; Geo longitude: 342, 5352 E) to improve IRI prediction by correcting the values of parameters B0 (B0 characterizes profile thickness) and B1 (B1 determines the form of the profiles). According to Szuszczewicz et al. (1995), IRI model does not exactly specify the characteristics of ionosphere plasma during disturbed magnetic activity and there is no data which allow IRI to provide results for equatorial latitude. The aim of the present work is to improve IRI 2001 TEC prediction in West African sector under different types of geomagnetic activity by comparing this IRI version prediction with CODG TEC maps at Niamey. The results of this work 


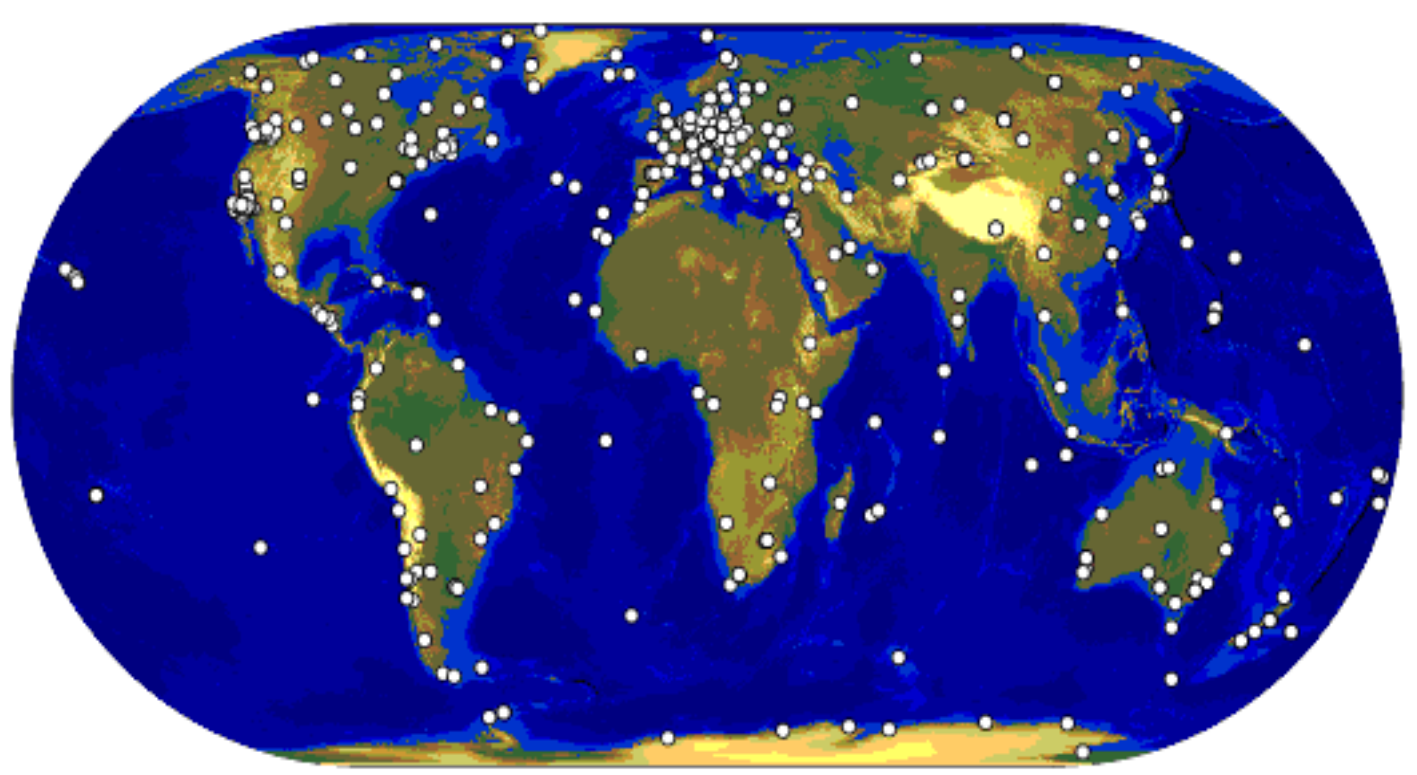

Figure 2. IGS GPS stations network (www.igscb.jpl.nasa.gov/network/).

may be interpreted as IRI prediction under different solar events (quiet days, shock and fluctuating activities: (Legrand and Simon, 1989; Simon and Legrand, 1989; Ouattara and Amory-Mazaudier, 2009) at Niamey. The main results suggest the necessity to make another study with long period of data in order to determine the profiles types of ionospheric parameters: 1) under different solar conditions, 2) for different seasons and 3) for different solar phases.

The paper is organized as follows: Subsequently, it devoted to CODG and IRI models; then it concerns materials and methods; the results of the paper are given thereafter and next we discuss the main results. The end of paper corresponds to the conclusion.

\section{CODG AND IRI MODELS}

CODG TEC maps are made by Centre for Orbit Determination in Europe (CODE). This centre is one of the centres of analysis of International GNSS Service (IGS) where GNSS stands for Global Navigation Satellite Systems. This centre publishes ionosphere maps (Schaer, 1997) and gives the correct GPS orbits, Earth orientation parameters and GPS stations coordinates and global ionosphere map namely global ionosphere maps (GIMs). CODG permits the determination of GPS TEC in specific region identified by its geographical coordinates by using IGS GPS network (Figure 2). CODG is an experimental model based on an ionospheric single layer model (SLM) (Norsuzila et al., 2008; Boutiouta et al., 2006). Single layer model assumes that free electrons are concentrated in a spherical scale with infinitesimal layer. The diameter of each grid is over $2000 \mathrm{~km}$ while the elevation angle is less than $20^{\circ}$. All CODG slant TEC values for selected stations (about 200 in the Earth) for one day are converted to CODG vertical TEC and tabulated in IONosphere Exchange (IONEX) format (Schaer, 1998). For that, it becomes possible to determine Vertical TEC wherever in the globe. IRI model is the reference model of lonosphere. Since its creation, it has been improved up to obtaining the version 2001. The improved model is given to the users every five years (Bertoni et al., 2006). Two principal subprograms CCIR (Comité Consultatif International des Radiocommunications, 1967, 1991) and URSI [Union Radio-Scientifique Internationale: (Rush et al., 1983, 1984, 1989; Fox and McNamara, 1988)] are destined to reproduce main parameters of ionosphere. IRI is used to conceive experimental measures, to estimate ionospheric environments and its effects and at last to validate different theory' hypotheses. This model is independent from theoretical hypotheses; it is built by taking into account confirmed experimental results (Obrou, 2008).

Generally, IRI model permits the determination of four principal parameters (Bilitza et al., 1979; Bilitza, 2001; Obrou, 2008): 1) electronic density, 2) electron temperature, 3) ions temperature and 4) positive ions density. As we found that the difference between CCIR and URSI predictions can be neglected here, we determine by means of CCIR option local hourly IRI TEC values by giving Niamey geographic coordinates and daily sunspot number value.

\section{MATERIALS AND METHODS}

\section{Data}

Workshop of IHY- Africa Space Weather Science and Education held in Addis Ababa during 12 to 16 November, 2007 
Table 1. Classification of IHY campaign days (March 21st to April 16th).

\begin{tabular}{|c|c|c|c|}
\hline \multirow{2}{*}{ Months } & \multirow{2}{*}{ Quiet } & \multicolumn{2}{|c|}{ Disturbed } \\
\hline & & Fluctuating & Shock \\
\hline \multirow{7}{*}{ March 2008} & 21 & \multirow[t]{7}{*}{29} & 26 \\
\hline & 22 & & 27 \\
\hline & 23 & & 28 \\
\hline & 24 & & \\
\hline & 25 & & \\
\hline & 30 & & \\
\hline & 31 & & \\
\hline \multirow{10}{*}{ April 2008} & Quiet & \multicolumn{2}{|c|}{ Disturbed: fluctuating } \\
\hline & 1 & \multicolumn{2}{|c|}{5} \\
\hline & 2 & \multicolumn{2}{|c|}{6} \\
\hline & 3 & \multicolumn{2}{|c|}{7} \\
\hline & 4 & \multicolumn{2}{|c|}{8} \\
\hline & 10 & \multicolumn{2}{|c|}{9} \\
\hline & 11 & \multicolumn{2}{|c|}{12} \\
\hline & 13 & \multicolumn{2}{|c|}{16} \\
\hline & 14 & & \\
\hline & 15 & & \\
\hline
\end{tabular}

decided that the period from 21st March to 16th April, 2008 is the period of the first heliosphere observed campaign (AmoryMazaudier et al., 2008). Data used in the present work concern CODG TEC maps and IRI 2001 TEC prediction values at Niamey for the period of IHY first campaign (Table 1).

\section{Methodology}

For data treatment, we take into account geomagnetic activity. Geomagnetic activity has been classified by many authors (Legrand and Simon, 1989; Simon and Legrand, 1989; Richardson et al., 2000; Richardson and Cane, 2002). Here we classify geomagnetic activity by using Legrand and Simon (1989) classification. Legrand and Simon (1989) based their classification on 2 facts: 1) the contribution of shock wave to geomagnetic activity and; 2) the strong correlation between Mayaud $(1971,1972,1973,1980)$ aa index and solar wind data (Svalgaard, 1977). They classified the solar wind speed in three classes (slow wind, fluctuating wind and high speed wind) and derived the following geomagnetic classes:

a) One class is defined as days with aa $<20 \mathrm{nT}$; this class corresponds to the slow speed solar wind $(\mathrm{V}<450 \mathrm{~km} / \mathrm{s})$ flowing continuously past the magnetosphere.

b) Three other classes concern disturbed geomagnetic activity (aa $>=20 \mathrm{nT}$ ); they follow morphological features of the solar phenomena. These classes are constituted by recurrent activity and two transient activities. We have:

\section{Recurrent (stream) activity}

It presents a continuing evolution during one solar rotation as well as during the following solar rotation. There is no sudden storm commencement (SSC) during the main phase. This class corresponds to high speed solar wind.

\section{Transient activity}

It is composed of two components, a first one related to very active spots on the solar disk (shock activity) and the second one due to the existence of fluctuating solar wind jets.

Shock activity class is determined by the special storms which arise by random bursts and without a recurrence of 27 days during 2,3 or 4 rotations. Fluctuating activity is determined by subtracting from the disturbed activity (aa $>20 \mathrm{nT}$ ), the shock activity and the recurrent activity. This class corresponds to fluctuating solar wind. In practice, to determine each day classification, they used pixel diagrams (for example pixel diagram of year 2008 as in Figure 3 ) of more than one century year (1868 to 1989). Each pixel diagram is built by using aa index values, sudden storm commencement (SSC) dates and the correlation between aa index values and solar wind data (Svalgaard, 1977). A pixel diagram helps to select the geomagnetic data as a function of the solar activity as described by solar rotation (27 days). Each pixel diagram has 31 rows corresponding to the maximum day of the month. To obtain the 31 rows, the first four rows have been repeated at the end. The diagram is started by reading from the third row and finished at the 29th row. The corresponding day of the third row has been mentioned on the left of the diagram and the corresponding year on the top of the diagram. Pixel diagram gives the dates of the SSC. These dates correspond to the dates of circled aa values in the diagram. If the concerning year corresponds to bissextile year, the letter B follows the name of the year (for example 2008 B in the pixel diagram of Figure 3). Shock event is estimated by taking into account 2 or 3 disturbed days after SSC date with aa $>40 \mathrm{nT}$ (non recurrent orange, red and olive red colours days with beginning SSC day). Shock event activity thus defined includes all of the different SSC class level such as S or R (Ouattara and Amory, 2009). Slow solar wind event is given by aa $<20 \mathrm{nT}$ (white and blue colour days). Recurrent activity is obtained by recurrent orange, red and olive red colours without beginning SSC during several Bartels rotations. The other cases contribute to fluctuating activity. A colour 


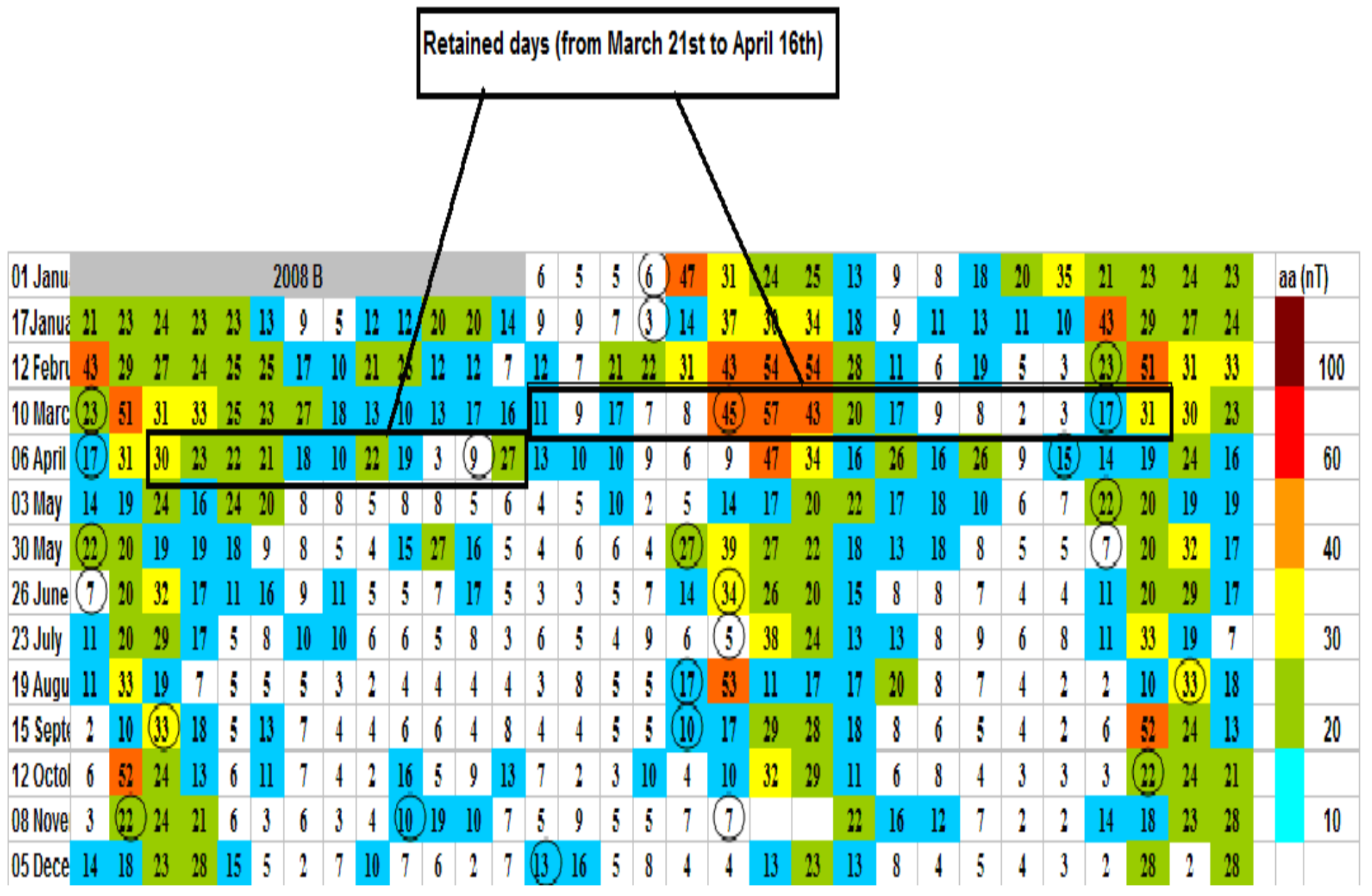

Figure 3. Pixel diagram of year 2008.

code helps as follows: quiet magnetic activity (aa $<10$ white, $10<=$ aa $<20$ blue), and disturbed magnetic activity $(20<=$ aa $<30$ : green; $30<=$ aa< 40: yellow; $40<=$ aa $<60$ : orange; $60<=$ aa $<100$ : red; aa $>$ $=100$ : olive red). Moreover for identifying solar sources of ionosphere features, Legrand and Simon (1989) clearly indicated how to proceed.

The whole process can also be found in the work of Legrand (1984). Solar source identification uses solar wind velocity, interplanetary magnetic field (IMF) intensity, shock wave, plasma density and aa index values. Moreover, Ouattara and Amory Mazaudier (2009) validated Legrand and Simon (1989) method (pixel diagrams built with aa index values) by using pixel diagrams built with solar wind velocity instead of geomagnetic aa index values. The validation consists of comparing their percentages (percentages obtained by using pixel diagrams) of each class of activity with those (percentages obtained by using solar wind velocity data) of Richardson et al. (2000) for the period of 1972 to 1986 and Richardson and Cane (2002) for the period of 1972 to 2000. For that, the purpose of this work is not to show the efficiency of Legrand and Simon (1989) method but to use this method to analyse and appreciate the predictions of CODG and IRI models. It can also be retained that the aim of this paper is not to establish the typical profile of each class of activity at Niamey but only to show if models are able to predict ionosphere responses to each type of solar events for a given time through case studies. For that, statistical analysis, in order to establish typical profiles, is out of the scoop of this paper. The retained period (from March 21st to April 16 th) for our study is indicated by black rectangles in Figure 4 . On the four classes of geomagnetic activity (quiet days activity, recurrent activity, shock activity and fluctuating activity) defined by Legrand and Simon (1989) and Simon and Legrand (1989), three classes of activity (quiet days activity, shock activity and fluctuating activity) are observed in Figure 4. For analyzing data we proceed as follows:

1) We analyze by means of CODG TEC maps temporal variations, the effect of different solar events (Figure 4). Here, we have slow solar winds which cause quiet activity, high solar wind streams which provoke recurrent activity and CMEs which produce shock activity) in Niamey ionosphere during IHY campaign project period. 2) We compare CODG TEC maps temporal variations with IRI TEC temporal variations under the three solar events conditions (Table 1 ) in order to determine on one hand $|R|$ predictions and on the other hand to appreciate theses results with the view of improving $I R I$ predictions in this region. For this comparison, we adopt two methods: a) morphological analysis or qualitative analysis. This analysis is based on the observation of the temporal profile variations (Figures $5 a$ and $b$ ). Morphological analysis allows us to debate on the physical processes during ionosphere dynamic:

b) Quantitative analysis. Here, we distinguish two types of analysis: b1) analyses with relative deviation module mean ( $\mathrm{rdmm})$; $\mathrm{rdmm}$ is 

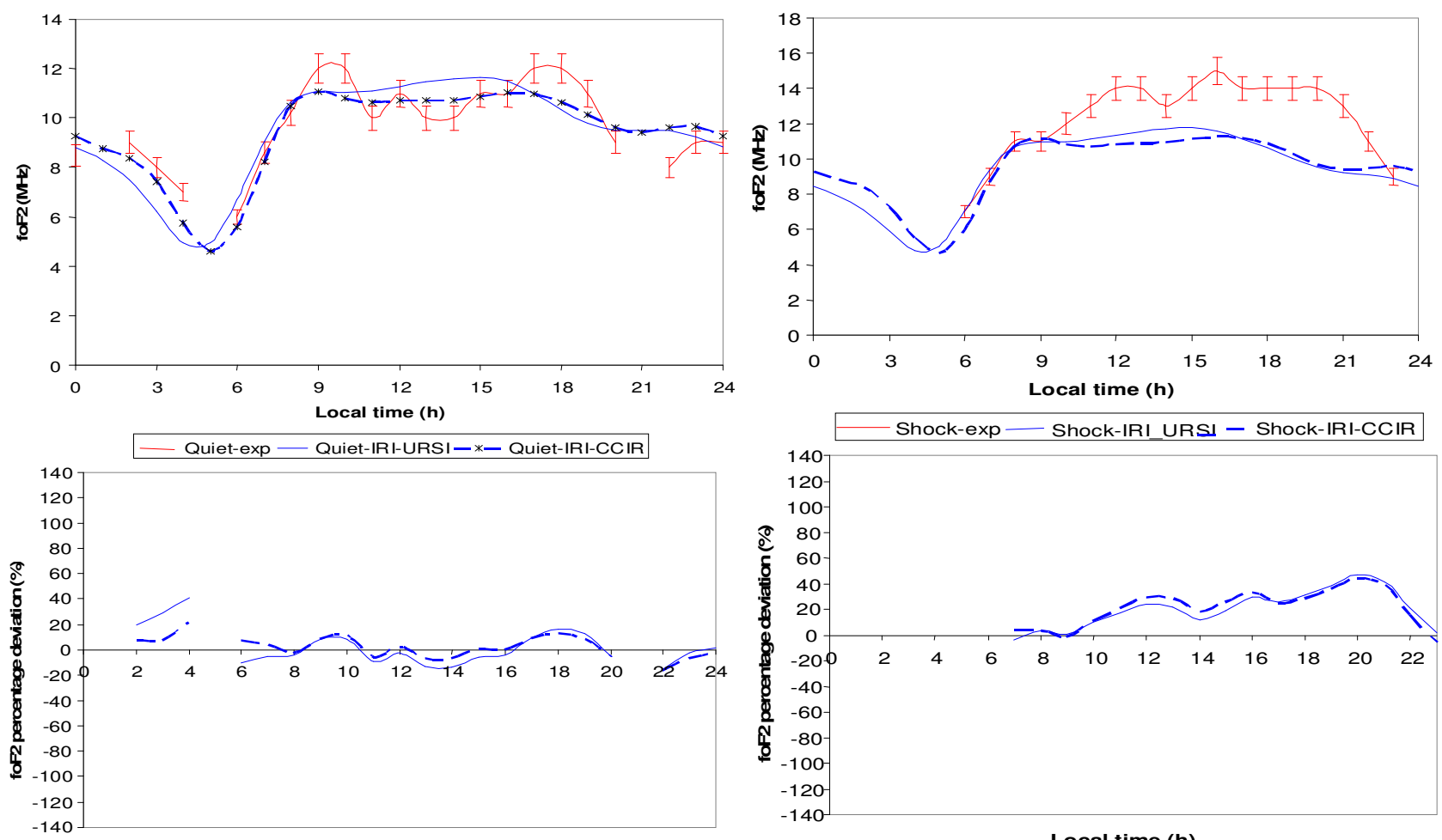

Local time (h)

\section{Local time (h)}

\%URSI-—\%CCIR

a) Quiet days

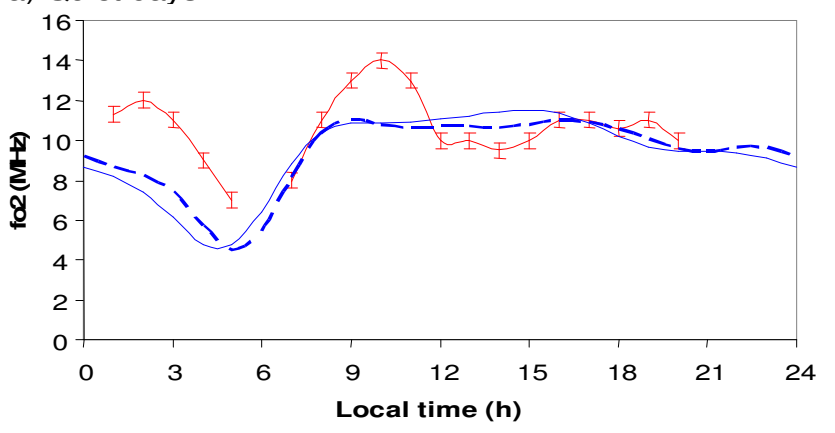

b) Shock activity
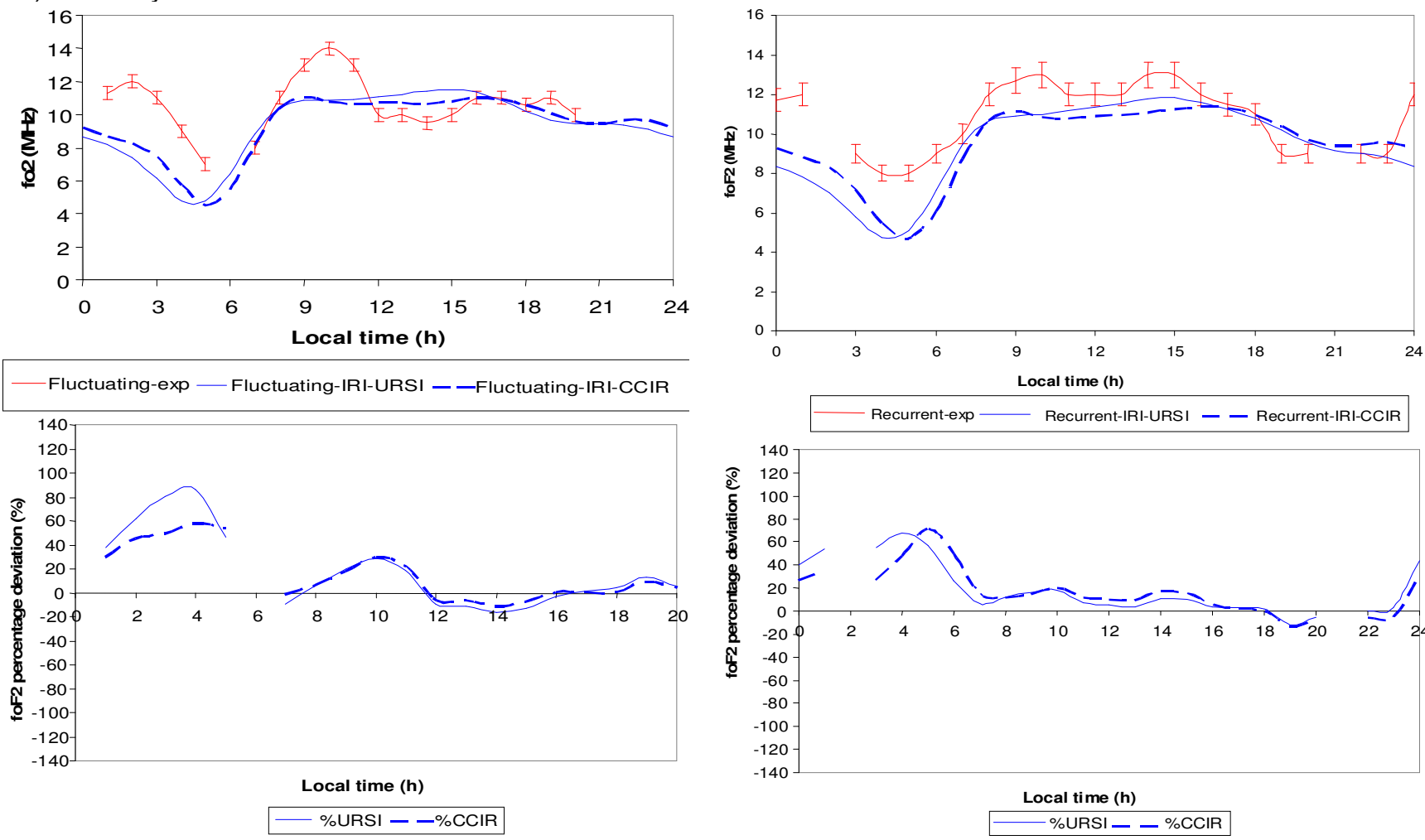

c) Fluctuating activity

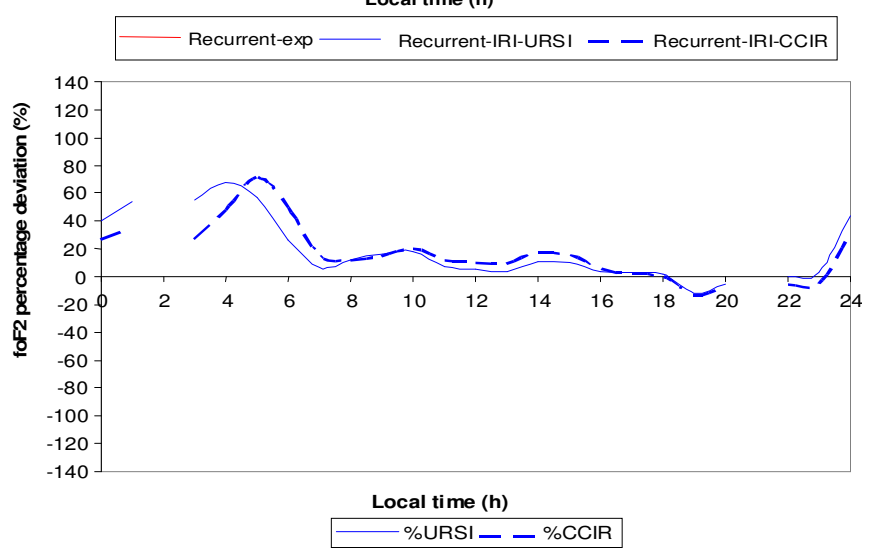

d) Recurrent activity

Figure 4. Comparison between IRI prediction and Ouagadougou foF2 ionosonde data for quiet day period (panel a), shock period (panel b), fluctuating period (panel c) and recurrent period (panel d). Top panels give foF2 graphs evolution with red full curve for experiment values, full blue line for URSI prediction and broken blue line for CCIR prediction while bottom panels corresponds to foF2 percentage deviation. 


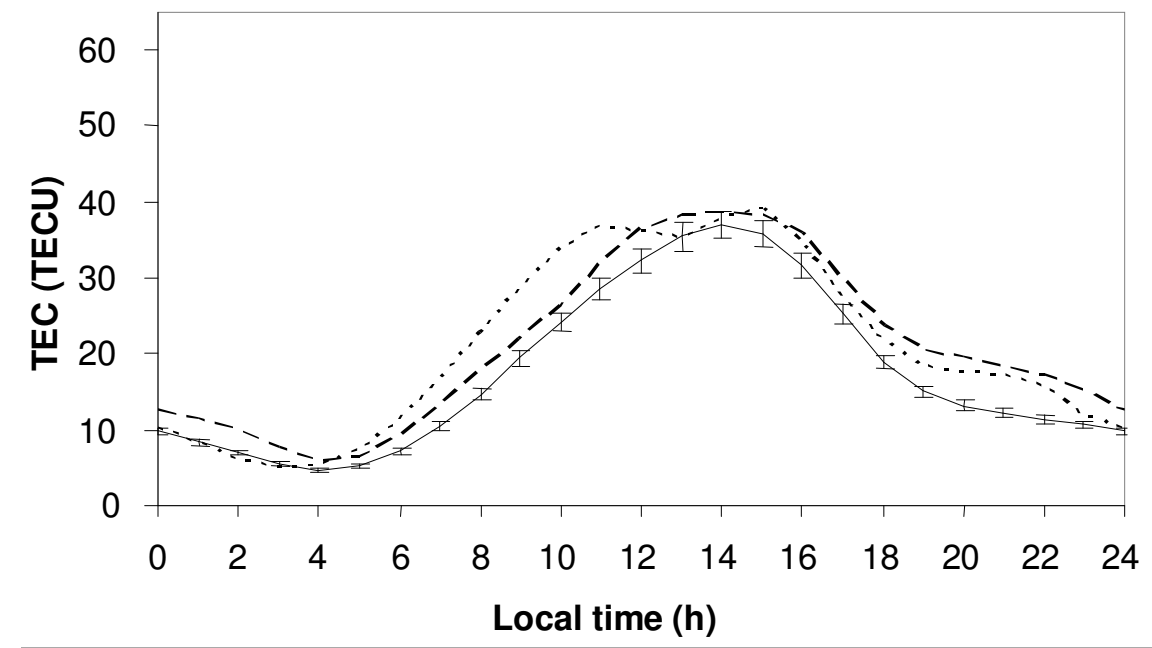

a)
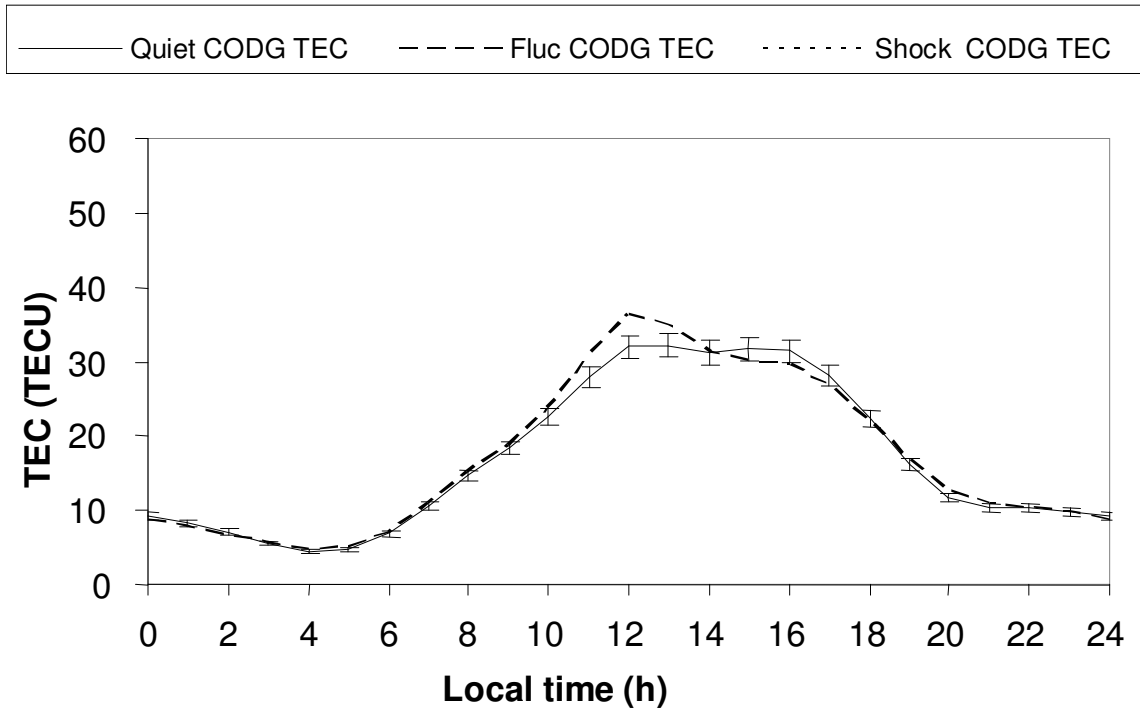

b)
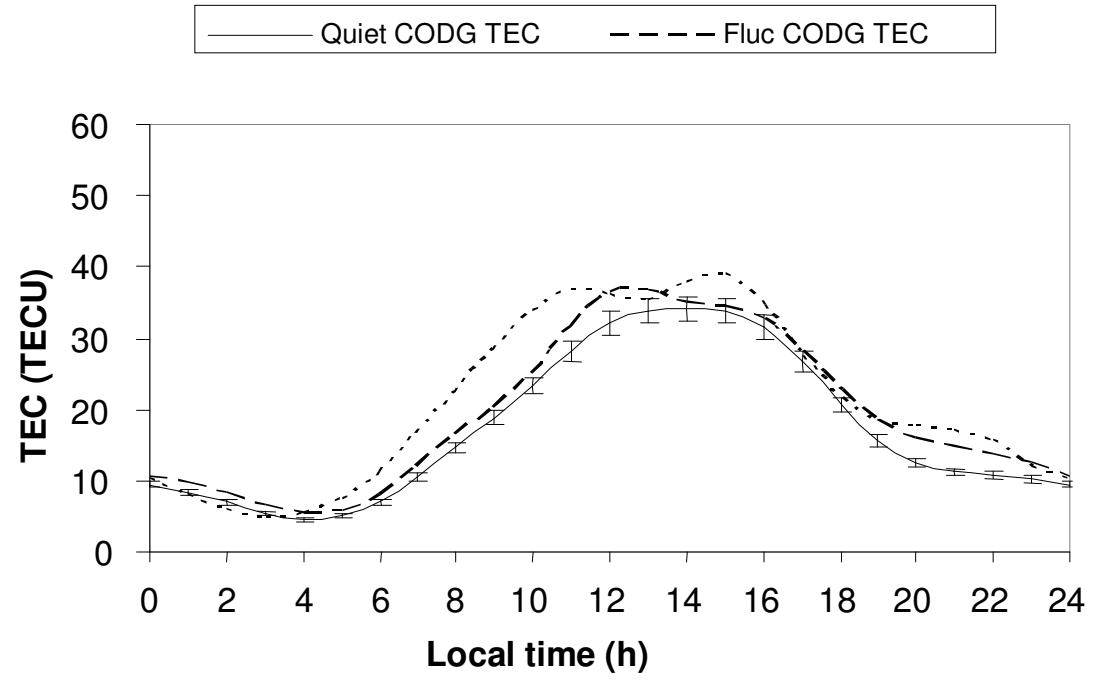

c)

Figure 5. CODG TEC maps time variation during IHY project period at Niamey for March (panel a); April (panel b) and the first IHY period (panel c) during quiet period (solid curve), fluctuating activity (broken curve) and shock period (CODG TEC time profile). 


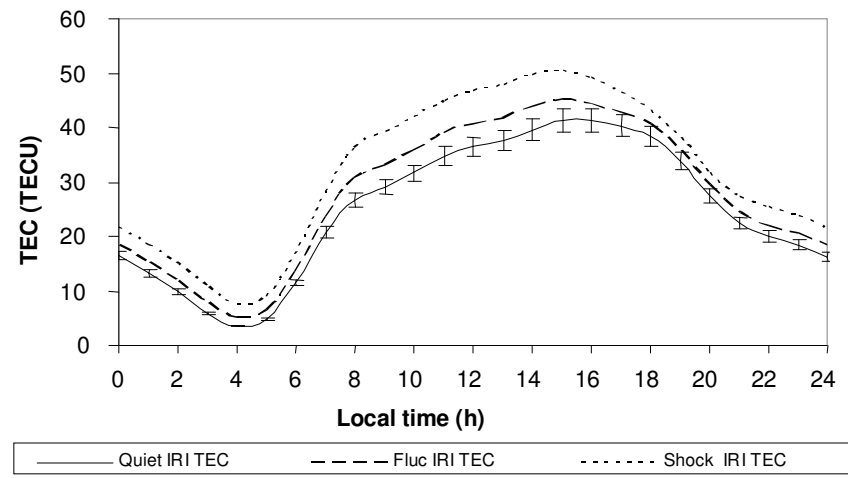

a)

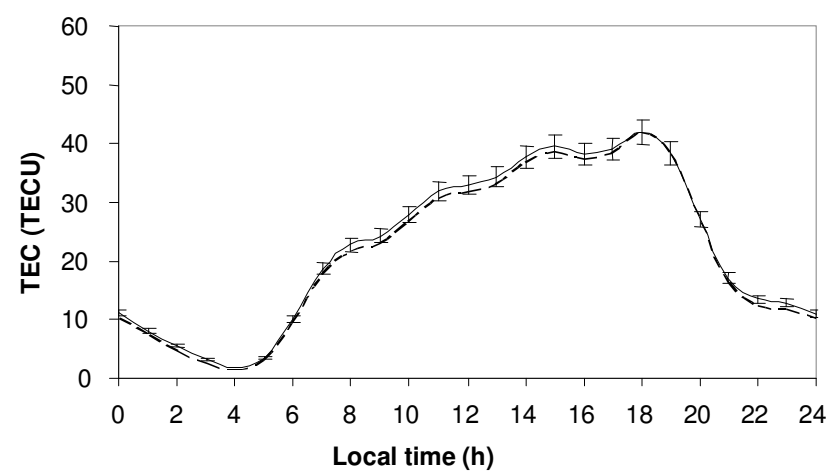

b)

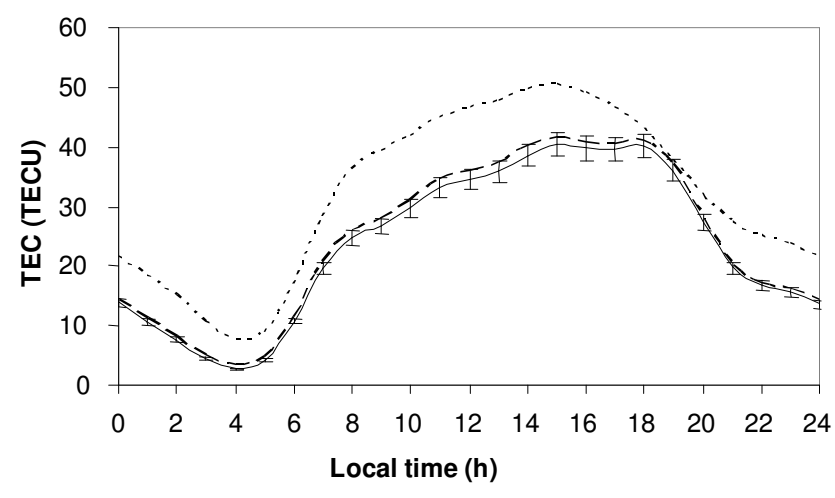

c)

Figure 6. CODG TEC maps time variation during IRI TEC project period at Niamey for March (panel a); April (panel b) and the first IRI TEC period (panel $c$ ) during quiet period (solid curve), fluctuating activity (broken curve) and shock period (CODG TEC time profile).

used in order to quantify the agreement/disagreement between the observed and modelled curves (Bertoni, 2004). Here, it highlights the quality of concordance between CODG TEC maps and IRI TEC;

rdmm is expressed as: $(\Delta)=\frac{1}{N} \sum_{i=1}^{N} \frac{\left|x_{i}^{o}-x_{i}^{m}\right|}{x_{i}^{o}}$ with $x_{i}^{o}$ and $x_{i}^{m}$ as CODG TEC maps and model IRI 2001 TEC predictions respectively and $\mathrm{N}$ the term number. If $\mathrm{rdmm}<=0.06$, then concordance goes from reasonable to good and for the reverse it goes from reasonable to bad (Bertoni et al., 2006).

b2) Analyses by means of percent deviation (Figure 6). This analysis quantifies the gap if any. The percent deviation is obtained by $\sigma_{r e l}=\frac{x_{i}^{o}-x_{i}^{m}}{x_{i}^{m}} \times 100$ with $x_{i}^{o}$ and $x_{i}^{m}$ as CODG TEC maps and model IRI 2001 predictions respectively. This method allows us to see the overestimation of the IRI TEC predictions $\left(\sigma_{r e l}<0\right)$ or/and the underestimation of the IRI TEC predictions $\left(\sigma_{r e l}>0\right)$.

\section{RESULTS}

In order to permit better choice of IRI subprogram to show IRI prediction during IHY period geomagnetic events, we analysed $|R|$ subprograms predictions with Ouagadougou station March/April foF2 mean values during decreasing solar phase for three solar cycles (1966 to 1998). The choice of Ouagadougou station lies on: 1) the existence of long series data; 2) the equatorial location of Ouagadougou station: the same as Niamey station location; and 3) the absence of long series data at Niamey. Figure 4 analysis shows that IRI prediction depends on geomagnetic conditions. IRI prediction is better during quiet period (top panel of Figure 4a) and recurrent period (top panel of Figure 4d). The worst prediction is shown during shock period (top panel of Figure $4 \mathrm{~b}$ ). For all graphs, the bad prediction of IRI can be seen before sunset. Only under shock period and during daytime IRI prediction is bad. Bottom panel of Figure $4 \mathrm{a}$ (quiet time) and of Figure 4c (fluctuating time) show that, during quiet time and fluctuating period, CCIR subprogram prediction is better than URSI prediction; for other bottom panels, it is the reverse. These results allow us to choose each type of subprogram according to each geomagnetic condition. For the following, whatever the type of geomagnetic class of activity, we simply design by IRI prediction of each type of IRI subprogram prediction according to its better prediction without mentioning the name of subprogram. As indicated previously, there are three classes of geomagnetic activity during IHY campaign project period: quiet days, shock and fluctuating classes of activity. By using pixel diagram shown in Figure 3, we determined day's classification (Table 1) according to solar events. In Figure 5, error bars in quiet profile allow us to appreciate the effect of disturbed solar events. In panel (Figure 5a), it can be seen that during quiet condition (solid curve), CODG TEC profile presents dome profile.

The maximum is located at 1400 LT with 36.99 TECU as TEC value. Fluctuating profile (broken curve) also shows dome profile. The maximum occurs at 1400 LT with 38.43 TECU as TEC value. This curve also shows night peak (2200 LT; 15.7 TECU). Shock profile (dotted curve) exhibits noon bite out profile with night peak (2100 LT; 17.1 TECU); in this profile we have morning peak (1000 LT; 36.8 TECU), evening peak (1500 LT; 39 TECU) and trough at $1300 \mathrm{LT}$ with 35.3 TECU. In Figure 
$5 b$, fluctuating activity profile presents morning peak while the profile of quiet days is plateau profile. In panel c, we show storm effects. Fluctuating and shock storms provoke positive storms. It can be seen that only shock storm profile (noon bite out profile) shows pre reversal enhancement. In Figure 6a, all profiles show the same patterns with fairly dome profile with evening maximum (1600 LT; 45.05 TECU). One can see four peaks: morning peak (0800 LT; 26.75 TECU), midday peak (1200 LT; 38.82 TECU), evening peak (1600 LT; 45.05 TECU) and night peak (2300 LT; 23.85 TECU). The presence of the latter peak expresses the pre reversal enhancement. We can assert that all disturbed activities produce positive storms. All day long, shock storm effect is higher than fluctuating one. From 0800 to 1600 LT whatever the storm, the disturbed effect is the same (we observe a constant gap between disturbed curve and quiet curve). Panel b graphs present five peaks: morning peak (0800 LT; 21.43 TECU), midday peak (1200 LT; 30.41 TECU) and two night peaks (1900 LT; 41.75 TECU and 2300 LT; 11.77 TECU). All graphs of Panel b exhibit the same behaviours with evening dominant double peaks (1500 LT; 38.39 TECU and 1900 LT; 41.75 TECU) and trough located at $1600 \mathrm{LT}$ with 37.57 TECU as TEC value. Panel $c$ shows that only shock graph shows pre reversal enhancement with evening peak. In Figures 7 , we make comparison between CODG TEC profile and IRI TEC profile. Figure 7a shows, for IRI TEC profile and CODG TEC profile, different patterns with evening peak: (1400 LT; 36.99 TECU) for CODG TEC and (1600 LT; 45.05 TECU) for IRI TEC; thus, IRI TEC profile presents its maximum $2 \mathrm{~h}$ later after CODG TEC graph with TEC gap 8.06 TECU. Morning peak (0800 LT; 26.75 TECU) is shown in IRI TEC profile. According to error bars, IRI TEC overestimates CODG TEC during quiet period at Niamey. Profiles of Figure $7 \mathrm{~b}$ present different patterns. These patterns are different from those of quiet days (Figure 7a) by the presence of night peaks: (2300 LT; 20.59 TECU) for IRI TEC graph and (2300 LT; 15.30 TECU) for CODG TEC graph. These graphs express the pre reversal enhancement. It can be seen in IRI graph morning peaks: (0800 LT; 30.60 TECU) and (1100 LT; 36.8 TECU).

The maximum peak is observed at $1400 \mathrm{LT}$ with 38.43 TECU for IRI graph and at 1500 LT with 45.05 TECU for CODG graph. The TEC gap at maximum peaks is 6.62 TECU. The graph different patterns are coming from storm actions. Figure 7c graphs have different patterns but all present evening peaks: (2200 LT; 15.7 TECU) for CODG graph and (2300 LT; 23.85 TECU) for IRI graph. The maxima of both curves which occur at the same time are (1500 LT; 45.05 TECU) for shock graph and (1500 LT; 39 TECU); TEC gap is 11.5 TECU. The analysis of Figure $7 \mathrm{a}$ exhibits the overestimation of IRI TEC predictions. Figure $7 \mathrm{~d}$ graphs present different patterns with plateau profile for CODG TEC graph and evening peak profile for IRI TEC graph. We show morning peak
(0800 LT; 22.75 TECU) and evening peak (1800 LT;41.95 TECU) in IRI TEC profile while CODG TEC profile present daytime peak (1300 LT; $32.21 \mathrm{TECU})$. The TEC gap value at the maximum of ionization is 9.74 TECU. This panel shows the overestimation of IRI except for pre sunrise period (0200 to 0500 LT). In Figure 7e, it emerges that IRI TEC profile shows morning peak (0800 LT; 21.43 TECU) and evening peak (1800 LT; 41.75 TECU) while CODG TEC profile shows only midday peak (1200 LT; 36.27 TECU). The gap of TEC at the maximum is 5.48 TECU. This panel shows the overestimation of IRI except for pre sunrise period (0200 to 0500 LT) and for daytime (1100 to 1300 LT). Figure $7 d$ and e shows the overestimation of $\mathrm{IRI}$ model with its amplification at evening.

\section{DISCUSSION}

It emerges from CODG TEC variation at Niamey (Figure 4) that, during these days, solar disturbed events produce positive storms, night peak and only shock event causes noon bite out TEC profile. We must conclude that during the decreasing phase of solar cycle 23 and for these days in March equinox at Niamey, only during shock event TEC profile highlights EXB effect and the other events show the disturbed effect of EXB by showing the maximum density instead of trough at midday. For the presence of night peak in TEC profile, disturbed activities provoke pre reversal enhancement. This post sunset enhancement is due to the enhancement in vertical drift. This phenomenon is explained in terms of the polarization fields produced by the large westward gradient of the ionospheric conductivity across the evening terminator (Prabhakaran et al., 2009). According to Farley (1986) theory, the pre reversal enhancement is caused by the fields produced to prevent negative charge accumulation at E-region sunset terminator (Cain et al., 1993). Our results are different from those of Ouattara (2009) who shows that during solar declining phase; only shock activity disturbed EXB effect in foF2 time profile at Ouagadougou. With error bars we are able to determine the impact of storms provoked by solar disturbed events. During March (panel a), disturbed geomagnetic activities produce positive storm except for shock activity which generates fairly negative storm at 0000 to $0400 \mathrm{LT}$. The period 0400 to $1100 \mathrm{LT}$ is characterized by shock activity (shock TEC is higher than fluctuating TEC) while for 0000 to $4400 \mathrm{LT}$ and 1500 to $0000 \mathrm{LT}$ we have fluctuating activity (fluctuating TEC is higher than shock TEC). We can underline that there is some difference in profile forms generated by these geomagnetic classes of activity. This highlights that solar events act differently in ionosphere and show the necessity to treat differently theses solar events instead of treating them together as disturbed day events.

In Figure 5, by considering error bars, it emerges that 


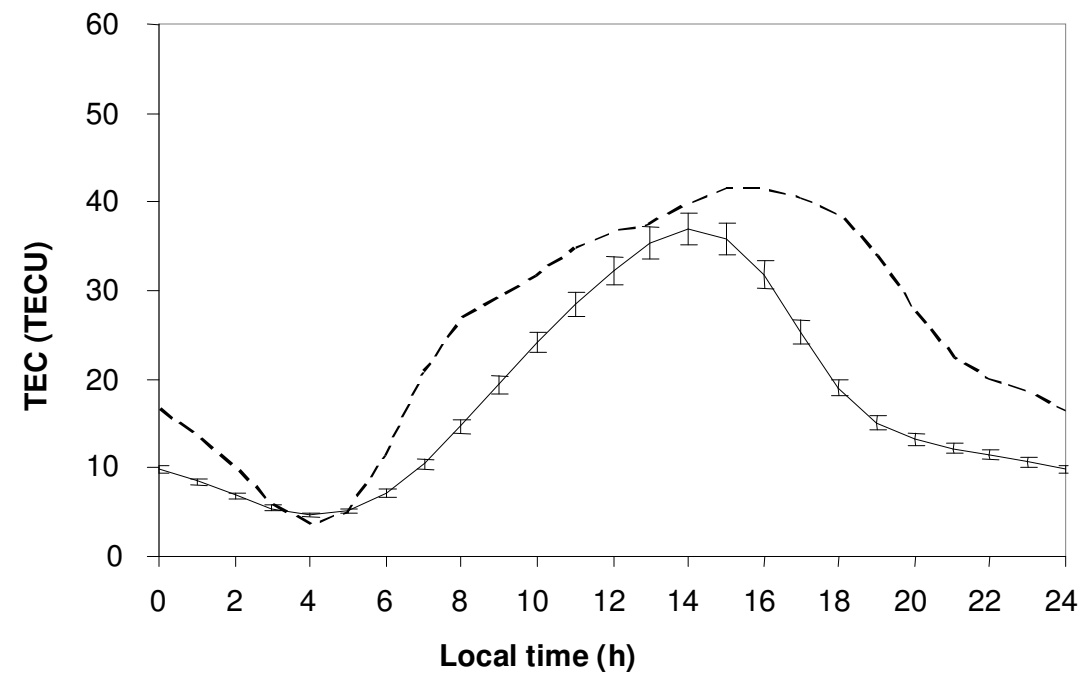

a) Quiet CODG TEC $\quad----$ Quiet IRI TEC

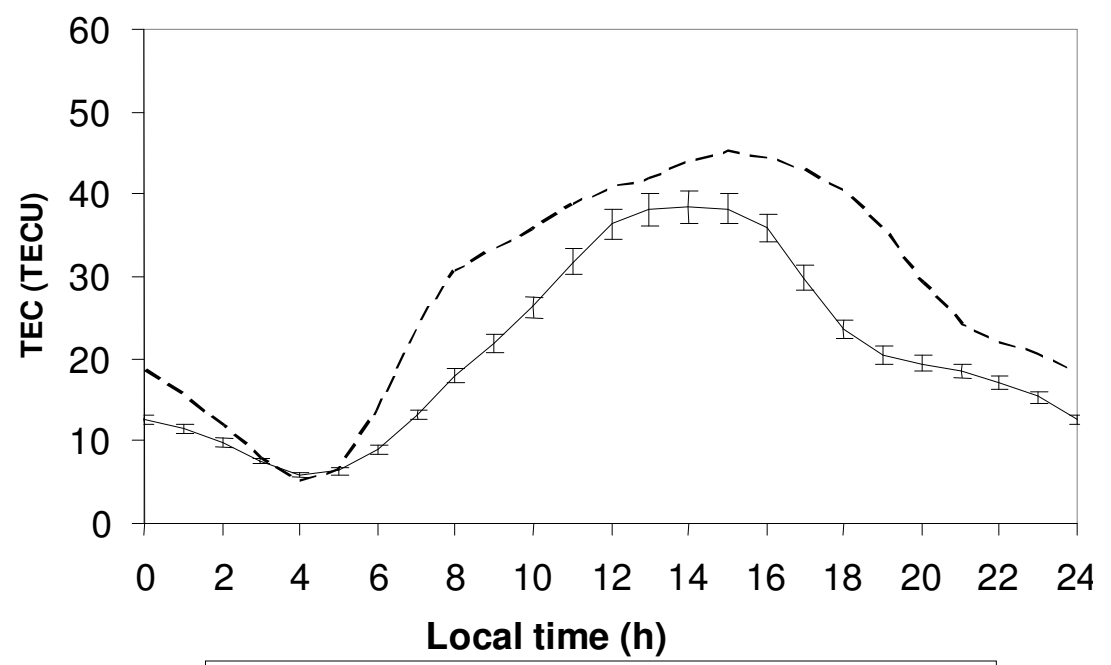

b) Fluc CODG TEC ---- Fluc IRI TEC

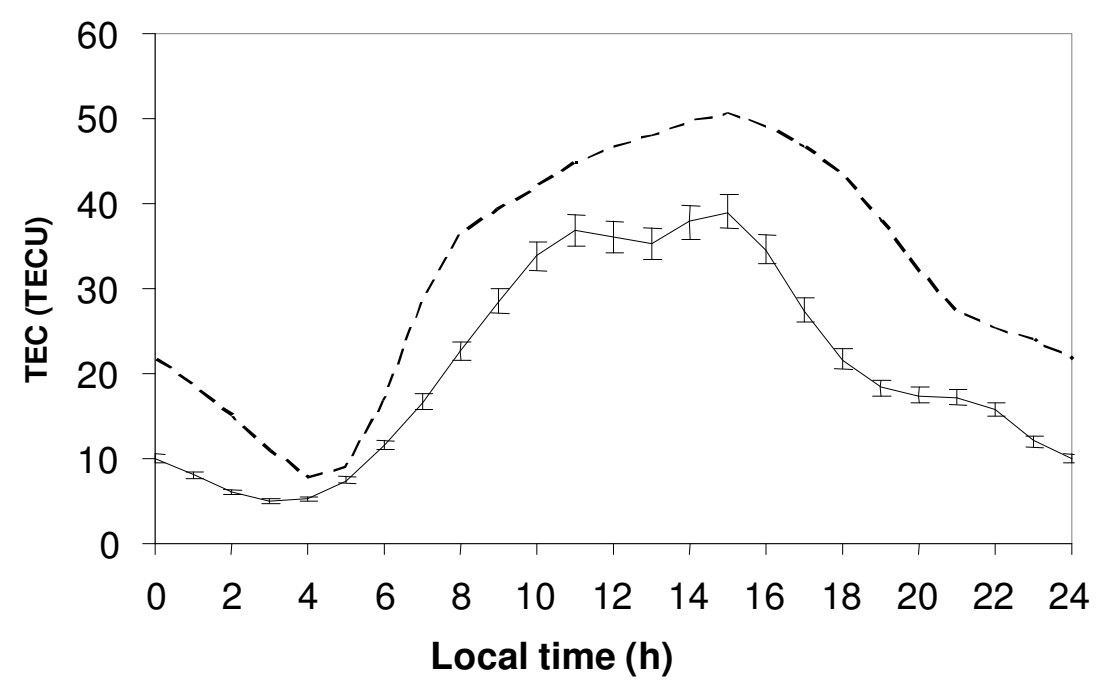

c) Shock CODG TEC $\quad----$ Shock IRI TEC 


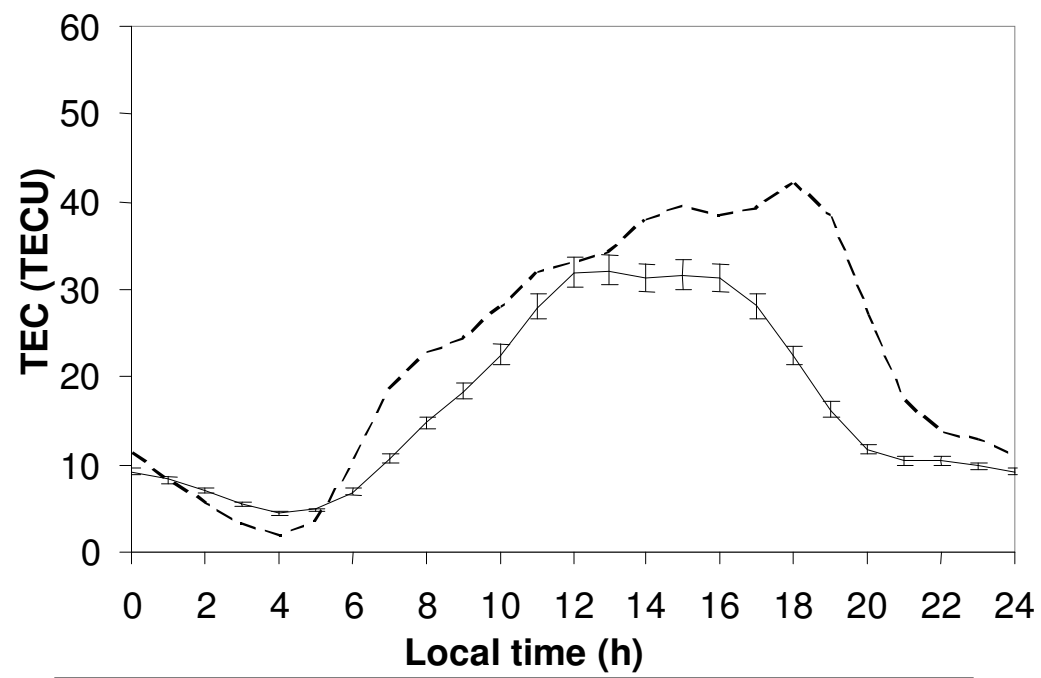

d)
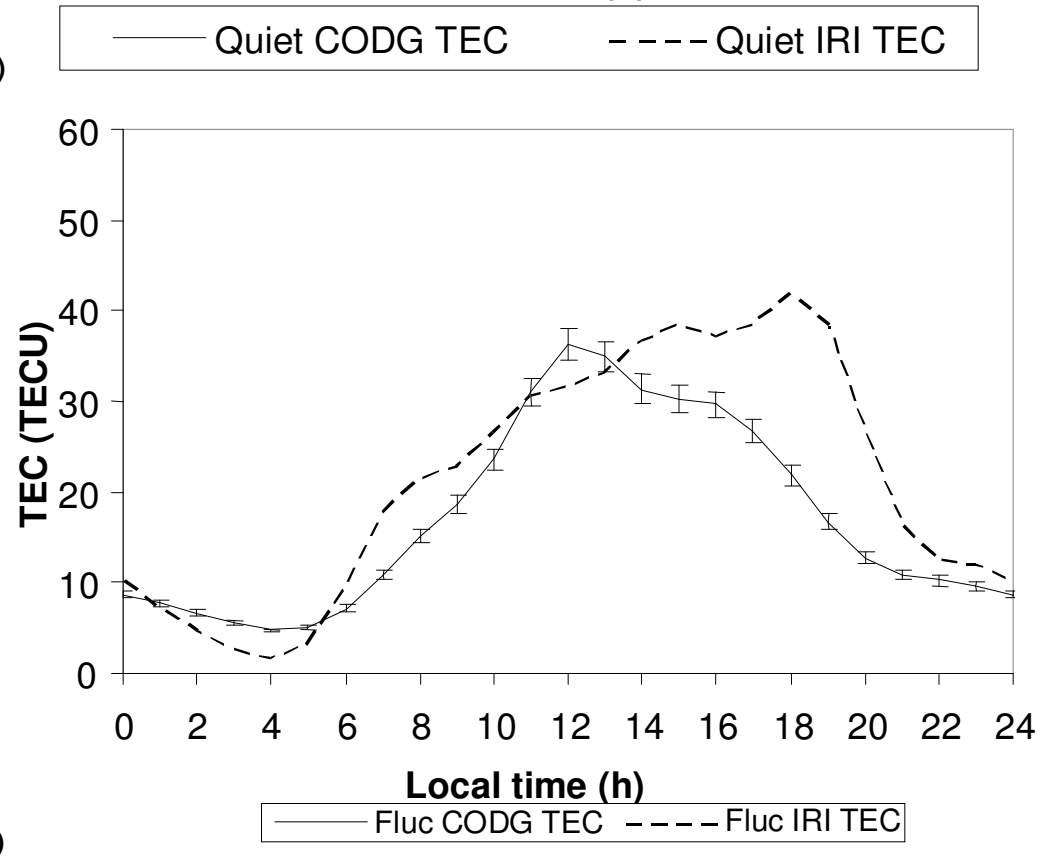

Figure 7. Comparison between CODG TEC maps and IRI 2001 TEC at Niamey station for quiet days (panel a), fluctuating days (panel b) and shock days (panel c) for March; (panel d), fluctuating days and (panel e) for April. Solid curve concerns CODG TEC maps and broken curve is devoted to IRI 2001 TEC.

fluctuating wind has no effect in ionosphere during April except at 1000 to 1300 LT where fairly positive storm is seen. For this month, there is no pre reversal enhancement. Because of the absence of the daytime trough in a profile (no noon bite out profile), E X B effect is disturbed. The difference between solar event effects (especially for fluctuating activity) during March and April (panels $a$, and b of Figure 5) may be due to the weak number of quiet days of March. IRI TEC variations at Niamey under different solar events (Figure 6) show that with IRI prediction, it becomes impossible to distinguish shock storm effect from fluctuating storm impact. May be it is the reason why storms are studied together. Moreover the comparison between the profiles of panels a, and c confirms that their difference is effectively due to a few number of fluctuating activity in March. This panel shows that the difference of all graphs is due to storm effect and not to a few number of fluctuating activity days in March. In Figure 7a the TEC time profile for quiet days is given. Panel $b$ of this figure concerns TEC time profile of fluctuating days. Shock TEC time profile is shown in Figure 7c. Panel a shows for IRI TEC profile and CODG TEC profile, different patterns with evening peak: (1400 LT; 36.99 TECU) for CODG TEC and (1600 LT; 45.05 
TECU) for IRI TEC; thus, IRI TEC profile presents its maximum $2 \mathrm{~h}$ later after CODG TEC graph with TEC gap 8.06 TECU. Morning peak (0800 LT; 26.75 TECU) is shown in IRI TEC profile. According to error bars, IRI TEC overestimates CODG TEC during quiet period at Niamey. Profiles of Figure $7 \mathrm{~b}$ present different patterns. These patterns are different from those of quiet days (Figure 7a) by the presence of night peaks: (2300 LT; 20.59 TECU) for IRI TEC graph and (2300 LT; 15.30 TECU) for CODG TEC graph. These graphs express the pre reversal enhancement. It can be seen in IRI graph morning peaks: (0800 LT; 30.60 TECU) and (1100 LT; 36.8 TECU). The maximum peak is observed at $1400 \mathrm{LT}$ with 38.43 TECU for IRI graph and at 1500 LT with 45.05 TECU for CODG graph. The TEC gap at maximum peaks is 6.62 TECU. The graph different patterns are coming from storm actions.

In panel $\mathrm{c}$, graphs have different patterns but all present evening peaks: (2200 LT; 15.7 TECU) for CODG graph and (2300 LT; 23.85 TECU) for IRI graph. The maxima of both curves which occur at the same time are (1500 LT; 45.05 TECU) for shock graph and (1500 LT; 39 TECU); TEC gap is 11.5 TECU. The analysis of Figure $7 a$ to $C$ exhibits the overestimation of IRI TEC predictions. The asymmetry observed in the overestimation amplitude of Figures $7 d$ to e graphs comes from the type of CODG TEC profile: fairly plateau profile in panel a and morning peak profile in panel b. Our results are different from those of Bertoni et al. (2006) in Palmas station (Geo latitude: $10.17^{\circ} \mathrm{S}$; Geo longitude: $48.20^{\circ} \mathrm{W}$ ) in Brazilian equatorial region. In fact, these authors showed that IRI 2001 always underestimates experimental values of foF2. Maybe the difference in the observations of Bertoni et al. (2006) and our observations: 1) comes from CODG TEC values which probably are fairly different from experimental TEC; and 2) are due to the nature of data involved in these studies: foF2 data for the study of Bertoni et al. (2006) and CODG TEC data for the present work even. In the objective of gap CODG TEC and IRI 2001 TEC quantification, we analyse the results of IRI 2001 by mean of rdmm and percentage deviation. rdmm values of March and April for quiet day periods respectively are 0.53 and 0.41 . These values are superior to 0.06 ; it can be concluded that the concordance between CODG TEC values and IRI 2001 TEC values goes from reasonable to bad. This result points out the necessity to improve IRI predictions for quiet. Moreover, IRI prediction is better in April than in March. During fluctuating period, rdmm values are 0.35 in March and 0.39 in April. These values show the same concordance variation like that of quiet day periods. Even if the necessity of improving model prediction appears from this result, it is important to underline that IRI predictions for fluctuating days are better than those of quiet periods. Here, IRI prediction is better in March than in April. When act CMEs, rdmm value is 0.67 , the same concordance variation is also shown here but the concordance is the worst. This result shows that for this kind of disturbed activity, IRI prediction needs important improvement.

In March, the best prediction occurs during fluctuating days and the worst during shock period. This kind of prediction for the most disturbed solar event confirms the assertion of Szuszczewicz et al. (1995) that is "IRI model does not exactly specify the characteristics of ionosphere plasma during disturbed magnetic activity...". By rdmm analysis, we quantify the gap for each type of disturbed events. The present results for quiet day periods show the necessity to use equatorial data to improve IRI model predictions. Because, there is no data which allow IRI to provide best results for equatorial latitude (Szuszczewicz et al., 1995), during IHY project, many GPS networks have been installed in African equatorial region (Figure 1). These results appear as an encouragement to continue to use equatorial data in IRI model data base in order to determine other parameters as Obrou (2008) uses to improve B0 and B1 value determinations. Figure 8 shows the percentage deviation variability for March (panel a) and for April (panel b). One can divide panel a' graphs time variations into three time intervals: before sunrise (0000 to 0700 LT); daytime (0700 to 1900 LT) and post sunset (1900 to $0000 \mathrm{LT}$ ). These three intervals show different behaviours of each kind of IRI predictions. Before sunrise, it appears that IRI prediction is the best during fluctuating activity and the worst during quiet period. For daytime, IRI prediction is the best during quiet period and the worst for shock activity. After sunset, IRI prediction is the best under fluctuating condition and the worst for quiet condition. For a day, the best prediction of IRI appears during quiet time. For the aforementioned observations, we can conclude that for a day, even if IRI fluctuating prediction is the best two third (before sunrise and post sunset) of time, and IRI quiet prediction is the best one third (daytime) of time, the day best prediction occurs during quiet time.

For mean point of view, in March, the best prediction occurs during fluctuating days as previously shown by rdmm analysis conclusion. For gap estimation, we can assert that, IRI TEC underestimates CODG TEC before sunrise $(0300$ to $0500 \mathrm{LT})$ when act solar slow wind and solar fluctuating wind; IRI TEC overestimates CODG TEC for the other times (daytime and post sunset) and during all three solar events. In panel $b$, day interval can be divided into three intervals: before sunrise (0000 to 0700 LT); daytime (0700 to 2000 LT) and post sunset (2000 to 0000 LT). It appears in three different behaviours. Before sunrise, quiet time prediction is better than fluctuating one. For daytime, quiet estimation is better than fluctuating one. For this time at midday, quiet IRI prediction is the same as quiet CODG estimation. From 1400 to 2000 LT, whatever the nature of solar event, IRI gives the same prediction. After sunset, the best prediction is shown under fluctuating period. For a day: 1) $\mathrm{IRI}$ best prediction is observed during quiet period all day long, 2) IRI best estimation is observed during daytime 
a)
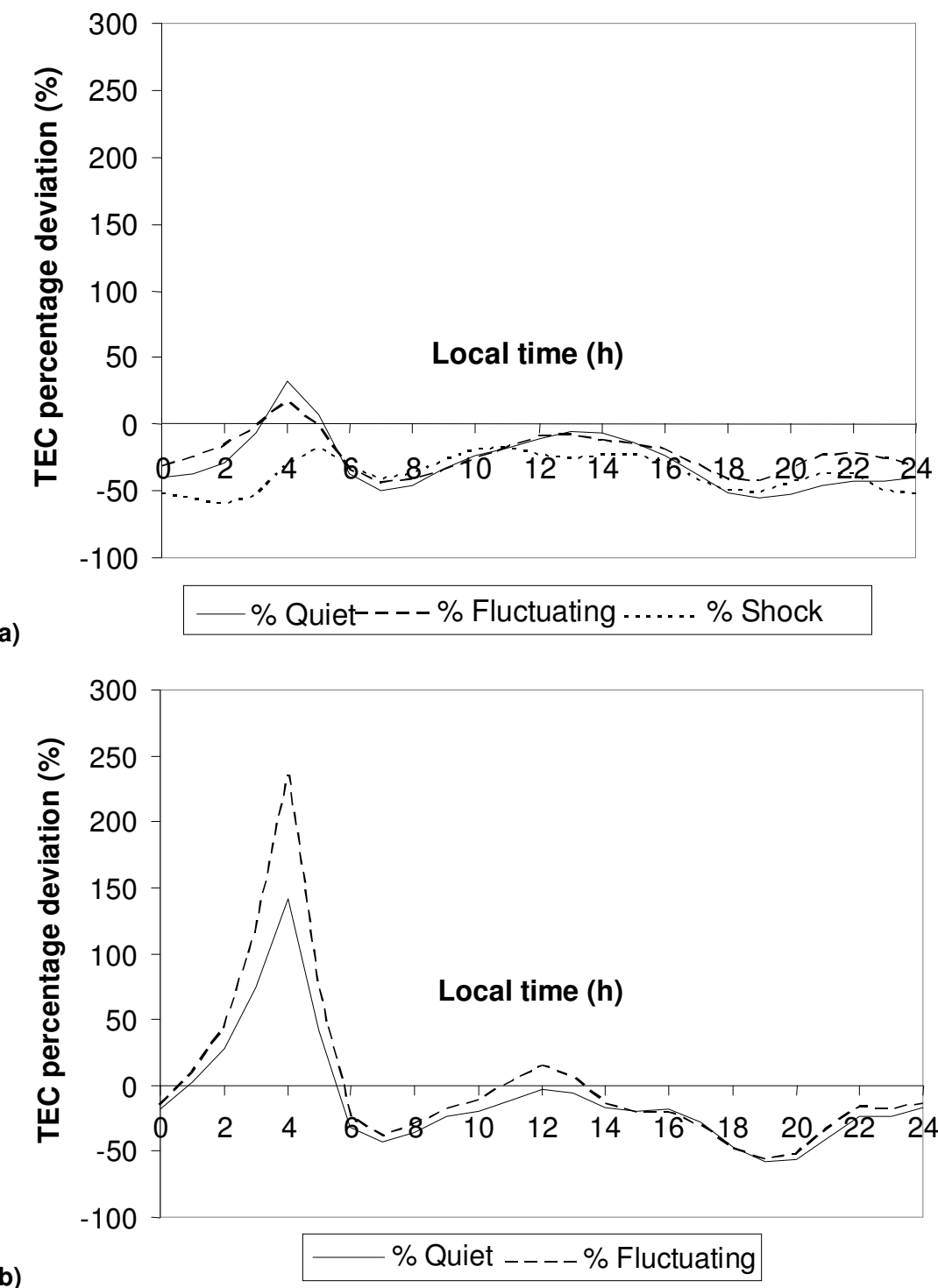

Figure 8. Comparative variation of percentage deviation at Niamey station for March (panel a) and April (panel b). Solid curve concerns quiet days, broken curve for fluctuating days and dotted curve for shock days.

for all solar events and; 3) IRI worst estimation appears before sunrise for all solar events. From mean point of view, percentage deviation shows best estimation of IRI during quiet solar wind events. This result is different from that of rdmm in April for what it is the reverse. These different results in April, between the two quantitative methods underline the necessity to analyse hourly model prediction values. For gap estimation, it can be said that for quiet period, IRI TEC underestimates CODG TEC before sunrise (0300 to 0600 LT) and overestimates CODG TEC for all other times (daytime and post sunset).

For fluctuating period, IRI TEC overestimates CODG TEC for 0000 to $0600 \mathrm{LT}$ and for 1100 to $1300 \mathrm{LT}$. For the other times, IRI TEC underestimates GPS TEC.

\section{Conclusion}

The present study shows that: 1) generally IRI 2001 model reproduces as well as TEC in West Africa equatorial region but it overestimates TEC values at Niamey station. 2) The response of IRI 2001 is better during fluctuating period than during quiet and shock day periods. 3) IRI 2001 underestimates Niamey CODG TEC values before $0600 \mathrm{LT}$, gives best between 1000 to 1400 LT and overestimates these CODG TEC values at 1800 to $2000 \mathrm{LT}$. These observations are not depending on geomagnetic condition. This result opens a new way to model with IRI during disturbed periods. Moreover, our results show the necessity to improve IRI model during 
quiet conditions and also during the whole disturbed conditions (shock and fluctuating). For, if the model takes into account experimental data, its improvement will be realised by: 1) considering the integration of data from African region obtained during $\mathrm{IHY}$ campaign and; 2) progressively by adding in its data base, data of the other operating stations.

\section{ACKNOWLEDGEMENTS}

Authors thank Prof. Olivier Kouadio Obrou from UFR SSMT of University of Cocody- Abidjan for providing IRI 2001 model. Authors also thank SRE editor and the reviewers for their helps and their advices which allow us to improve the paper.

\section{REFERENCES}

Anderson DN, Mendillo M and Herniter B (1985). A semi-empirical, lowlatitude ionospheric model, Tech. Rep. AFGL-TR-85-0254, Air Force Geophysics Laboratory, Hanscom AFB, Massachusetts.

Anderson DN, Decker DT and Valladares CE (1996). Handbook of Ionospheric Models, chap. Global theoretical ionospheric model (GTIM), r. w. schunk ed.,Utah State University, Logan, Utah, pp.133152

Amory-Mazaudier C, Basu S, Bock, Combrink A, Groves K, Fuller Rowell T, Lassudrie-Duchesne P, Petitididier M, Yizengaw E (2008): International Heliophysical Year: GPS Network in Africa, Earth Moon Planet, DOI 10.1007/s11038-008-9273-8

Bertoni $F$ (2004). Ionospheric drifts in equatorial latitudes: Observation and modelling, Ph.D. Thesis, National institute for space research, Sao José dos Campos, Brazil.

Bertoni F, Sahai Y, Lima WLC, Fagundes PR, Pillat VG, BeckerGuedes F, Abalde JR (2006). IRI-2001 model predictions compared with ionospheric data observed at Brazilian low latitude stations, Ann. Geophys., 24: 2191-2200.

Bilitza D (2001). International Reference Ionosphere 2000, Radio Sci., 36: 261-275.

Bilitza D, Sheikh M, Eyfrig R (1979). A global model for the height of the F2-peak using $M(3000) F 2$ values from the CCIR numerical map, Telecomm. J., 46: 549-553

CCIR (1991). Atlas of ionospheric characteristics, Comité Consultatif International des Radiocommunications, Report, pp.340-634, Int. Telecommun. Union, Geneva.

CCIR (1967). Atlas of Ionospheric Characteristics, Comit'e Consultatif International des Radiocommunications, Report, pp. 340-344, Int. Telecommun. Union, Geneva.

Cain DJ, Heelis RA, Bailey GJ (1993). Effect of electrical coupling on equatorial ionospheric plasma motions: When is the $F$ region a dominant driver in the low-latitude dynamo, J. Geophys. Res., 98 (A4): 6033-6037.

Daniel RJ, Brown L, Anderson D, Fox M, Doherty P, Decker D, Sojka J, Schunk R (1995). Parameterized ionospheric model: A global ionospheric parameterization based on first principles models, Radio Sci., 30: 1499-1510

Farley DT, Bonelli E, Fejer BG, Larsen MF (1986). The pre-reversal enhancement of the zonal electric field in the equatorial ionosphere, J. Geophys. Res., 91: 13723-13728

Fleury R (2010). Training for the use of GPS in Africa, leading to ionospheric studies, the Brest National Telecommunications School.

Fox MW, McNamara LF (1988). Improved World-Wide Maps of Monthly Median foF2, J. Atmos. Terr. Phys., 50: 1077-1086.
Legrand JP, Simon PA (1989). Solar cycle and geomagnetic activity: A review for geophysicists. Part I. The contributions to geomagnetic activity of shock waves and of the solar wind. Ann. Geophys. 7(6) : 565-578.

Legrand JP (1984). Elementary introduction of cosmic physics and solar terrestrial physics, area of southern and antarctic French land, p. 306.

Mayaud PN (1971). A measurement of planetary magnetic activity based on two antipodal observatories, Ann. Geophys. 27(71).

Mayaud PN (1972). The aa indices: a 100-year series, characterizing the magnetic activity, J. Geophys. Res. 77(34): 6870-6874

Mayaud PN (1973). A hundred year series of geomagnetic data, indices aa, Storm sudden commencements, IAGA Bull. (IUGG Publ. Office, Paris, Mayaud), 33(252): 1868-1967,

Mayaud PN (1980). Derivation, Meaning, and Use of Geomagnetic Indices, Geophys. Monogr. Ser., vol. 22, AGU, Washington, D. C.

Obrou KO (2008). Equatorial Ionosphere: Contribution to the improvement of model "International Reference lonosphere" (IRI), Super PhD in physical sciences, UFR SSMT, University of Cocody.

Ouattara $F(2009)$. Contribution to the study of the relationship between the two conponents of solar magnetic field and equatorial ionosphere. Super PhD. Cheikh Anta Diop University of Dakar, Senegal, p. 348.

Ouattara F, Amory-Mazaudier C (2009). Solar-geomagnetic activity and Aa indices toward a standard classification, J. Atm. Solar-Terr. Phys., 71:1736-1748.

Ouattara F, Amory-Mazaudier C, Fleury R, Lassudrie-Duchesne P, Vila $P$, Peitididier M (2009): West African equatorial ionospheric parameters climatology based on Ouagadougou ionosonde station data from June 1966 to February 1998, Ann. Geophys., 27(6): 25032514.

Prabhakaran Nayar SR, Mathew TJ, Sreehari CV, Sumod SG, Devasia CV, Ravindran R, Sreeja V, Kumar Pant T, Sridharan R (2009). Electrodynamics of the equatorial F-region ionosphere region during pre-sunrise period, Ann. Geophys., 27: 107-111.

Rush CM, Fox M, Bilitza D, Davies K, McNamara L, Stewart F, pokempner $\mathrm{M}$ (1989). Ionospheric mapping: an update of foF2 coefficients, Telecomm. J., 56: 179-182.

Rush CM, Pokempner M, Anderson DN, Perry JC, Stewart FG, Reasoner R (1984). Maps of foF2 Derived from Observations and Theoretical Data, Radio Sci. 19: 1083-1097.

Rush CM, Pokempner M, Anderson DN, Stewart FG, Perry JC (1983). Improving lonospheric Maps Using Theoretically Derived Values of foF2, Radio Sci., 18: 95-107.

Schaer S (1997): How to use CODE's Glaobal Ionosphere Maps, unpublished paper, Astronomical Institute, university of Berne.

Schunk RW (Ed.) (1996): Handbook of Ionospheric Models, chap. A coupled thermosphere-ionosphere model (CTIM), Utah State University, Logan, Utah. pp. 217-238.

Simon PA, Legrand JP (1989). Solar cycle and geomagnetic activity: A review for geophysicists. Part II. The solar sources of geomagnetic activity and their links with susnspot cycle activity. Ann. Geophys. 7(6): 579-594.

Svalgaard L (1977). Geomagnetic activity: dependence on solar wind parameters, in Coronal holes and high speed wind streams, edited by J.B. ZIRKER, (Colorado Ass. Univ. Press. Boulder). 371-432.

Szuszczewicz EP, Roble RG, Wilkinson P, Hanbaba R (1995). Coupling mechanisms in the lower ionospheric-thermospheric system and manifestation in the formation and dynamics of intermediate and descending layers, J. Atmos. Terr. Phys., 57(12): 1483-1496. 